\title{
Promising new baseflow separation and recession analysis methods applied to streamflow at Glendhu Catchment, New Zealand
}

\author{
M. K. Stewart \\ Aquifer Dynamics \& GNS Science, P.O. Box 30368, 5040 Lower Hutt, New Zealand \\ Correspondence to: M. K. Stewart (m.stewart@gns.cri.nz) \\ Received: 24 May 2014 - Published in Hydrol. Earth Syst. Sci. Discuss.: 27 June 2014 \\ Revised: 16 April 2015 - Accepted: 12 May 2015 - Published: 2 June 2015
}

\begin{abstract}
Understanding and modelling the relationship between rainfall and runoff has been a driving force in hydrology for many years. Baseflow separation and recession analysis have been two of the main tools for understanding runoff generation in catchments, but there are many different methods for each. The new baseflow separation method presented here (the bump and rise method or BRM) aims to accurately simulate the shape of tracer-determined baseflow or pre-event water. Application of the method by calibrating its parameters, using (a) tracer data or (b) an optimising method, is demonstrated for the Glendhu Catchment, New Zealand. The calibrated BRM algorithm is then applied to the Glendhu streamflow record. The new recession approach advances the thesis that recession analysis of streamflow alone gives misleading information on catchment storage reservoirs because streamflow is a varying mixture of components of very different origins and characteristics (at the simplest level, quickflow and baseflow as identified by the BRM method). Recession analyses of quickflow, baseflow and streamflow show that the steep power-law slopes often observed for streamflow at intermediate flows are artefacts due to mixing and are not representative of catchment reservoirs. Applying baseflow separation before recession analysis could therefore shed new light on water storage reservoirs in catchments and possibly resolve some current problems with recession analysis. Among other things it shows that both quickflow and baseflow reservoirs in the studied catchment have (non-linear) quadratic characteristics.
\end{abstract}

\section{Introduction}

Interpretation of streamflow variations in terms of catchment characteristics has been a major theme in hydrology for many years in order to improve catchment and stream management. Two of the main tools for this task are baseflow separation and recession analysis (Hall, 1968; Brutsaert and Nieber, 1977; Tallaksen, 1995; Smakhtin, 2001). Baseflow separation aims to separate streamflow into two components (quickflow and baseflow), where quickflow is direct runoff following rainfall, and baseflow is delayed streamflow during periods without rain. Recession analysis aims to model the decrease of streamflow during rainless periods to extract parameters descriptive of water storage in the catchment. In a similar way, transit time analysis determines transit time distributions of water in the stream and catchment in order to quantify flowpaths and storages through the catchment. To fully understand and satisfactorily model the movement of water and chemicals through catchments, it is necessary to understand in detail the water stores and flowpaths (Fenicia et al., 2011; McMillan et al., 2011; Beven, 2012; Hrachowitz et al., 2013).

The technique of baseflow separation has a long history in practical and scientific hydrology because knowledge about baseflow is very useful in predicting low-flow progressions and understanding water quality variations. Although considered to some extent arbitrary by some (e.g. Hewlett and Hibbert, 1967; Beven, 1991), most of the methods yield results that are quite similar (e.g. Gonzales et al., 2009 obtained long-term baseflow fractions (i.e. baseflow indexes, called BFIs below) ranging from 0.76 to 0.91 for nine nontracer baseflow separation methods, not too different from their tracer-based result of 0.90), and all show that baseflow is often quantitatively important in annual flows and, of 
course, very important during low flows. This work contends that baseflow should also be specifically considered during intermediate and high flows, because streamflow during such events is composed of comparable amounts of both quickflow and baseflow (e.g. Sklash and Farvolden, 1979) and they are produced by very different mechanisms. Consequently, it is believed that process descriptors such as hydrographrecession constants (or transit time distribution parameters) should be determined on separated components as well as total streamflow during such flows, because streamflow is a mixture and therefore can give misleading results. All such process descriptors should be qualified by the components they were derived from. Putting it simply, the contention is that to properly understand the early streamflow recession hydrograph it is first necessary to separate it into its quickflow and baseflow components. While this may be considered obvious by some, recession analysis has not previously been applied to other than the total streamflow.

Recession analysis also has a long history for practical hydrology reasons, but Stoelzle et al. (2013) recently highlighted large discrepancies between different methods of analysis, in particular contrasting recession parameters derived by the methods of Brutsaert and Nieber (1977), Vogel and Kroll (1992), and Kirchner (2009). Stoelzle et al. (2013) suggested that "a multiple methods approach to investigate streamflow recession characteristics should be considered". This indicates that there is little general consensus on how best to apply recession analysis to streamflow.

This paper presents a new method of baseflow separation (called the bump and rise method or BRM) which aims to accurately simulate the shape of tracer-determined baseflow or pre-event water. The two BRM parameters are calibrated by (a) fitting to tracer data if it is available, or (b) using an optimising process if it is not. The calibrated BRM filter is then applied to the streamflow record. Two other baseflow separation methods (those of Hewlett and Hibbert, 1967, and Eckhardt, 2005) are compared with the BRM. The paper also takes a fresh look at the application of recession analysis for characterising runoff generation processes. Recession analysis of streamflow can give misleading slopes on a recession plot particularly at intermediate flows because streamflow is a varying mixture of components (at the simplest level, quickflow and baseflow). When quickflow, baseflow and streamflow are all analysed, the effect of the more rapidly receding quickflow on the streamflow can be seen. The same procedure gives insight into the processes of streamflow generation at each exceedance percentage when applied to flow duration curves (Sect. 2.4). The methods are illustrated using streamflow data from the Glendhu Catchment in Otago, South Island, New Zealand.

\section{Methods and study site}

\subsection{Baseflow separation}

Justification for making baseflow separations rests on the dissimilarity of quickflow and baseflow generation processes in catchments (e.g. Hewlett and Hibbert, 1967). Evidence of this is given by the different recession slopes, and chemical and stable isotope compositions of early and late recessions in hydrographs (examples are given for Glendhu, see below). In addition, transit times of stream water show great differences between quickflow and baseflow. While quickflow is young (as shown by the variations of conservative tracers and radioactive decay of tritium), baseflow can be much older with substantial fractions of water having mean transit times beyond the reach of conservative tracer variations (4 years) and averaging 10 years as shown by tritium measurements (Stewart et al., 2010, 2012; Michel et al., 2015). For these reasons, it is believed that it is not justifiable to treat the streamflow as a single component, but that at least two components should be considered by applying baseflow separation to the hydrograph before analysis.

Streamflow at any time $\left(Q_{t}\right)$ is composed of the sum of quickflow $\left(A_{t}\right)$ and baseflow $\left(B_{t}\right)$

$Q_{t}=A_{t}+B_{t}$,

where time steps are indicated by the sequences $Q_{t-1}, Q_{t}$, $Q_{t+1}$, etc. The time increment is $1 \mathrm{~h}$ in the examples given below, but can be days in larger catchments or any regular interval. Quickflow or direct runoff results from rainfall events and often drops to 0 between events, while baseflow is continuous as long as the stream flows. As shown by the names, the important distinction between them is the time of release of water particles to the stream (i.e. their transit times through the catchment). They are supplied by fast and slow drainages within the catchment, direct precipitation and fast storage reservoirs (soil stores) supply quickflow, and slow storage reservoirs (mainly groundwater aquifers) supply baseflow. This simple separation has proven to be effective in many catchments, and is practical for the general case considered here. However, particular catchments may have a variety of different possible streamflow components that could be separated in principle. Figure 1 gives a recession curve as an example showing schematically the two flow components and the early and late parts of the curve. The late part of the recession curve starts when baseflow dominates streamflow (i.e. quickflow becomes very small).

Many methods have been developed for baseflow separation (see reviews by Hall, 1968; Tallaksen, 1995; Gonzales et al., 2009). Baseflow separation methods can be grouped into three categories: analytical, empirical and chemical/isotopic or tracer methods. Analytical methods are based on fundamental theories of groundwater and surface water flows. Examples are the analytical solution of the Boussinesq equation, the unit hydrograph model and theories for reservoir 


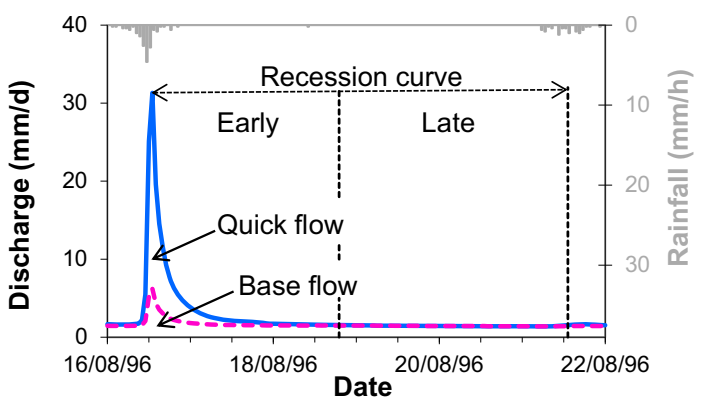

Figure 1. Quickflow and baseflow components of streamflow, and the early and late parts of the recession curve. Quickflow is represented by the area between the streamflow and baseflow curves, and baseflow is the area under the baseflow curve.

yields from aquifers (Boussinesq, 1877; Su, 1995; Nejadhashemi et al., 2003). Empirical methods based on the hydrograph are the most widely used (Zhang et al., 2013), because of the availability of such data. The methods include (1) recession analysis (Linsley et al., 1975), (2) graphical methods, filtering streamflow data by various methods (e.g. finding minima within predefined intervals and connecting them, Sloto and Crouse, 1996), (3) low-pass filtering of the hydrograph (Eckhardt, 2005; Zhang et al., 2013), and (4) using groundwater levels to calculate baseflow contributions based on previously determined relationships between groundwater levels and streamflows (Holko et al., 2002).

One widely used empirical method for small catchments was proposed by Hewlett and Hibbert (1967) who argued that "since an arbitrary separation must be made in any case, why not base the classification on a single arbitrary decision, such as a fixed, universal method for separating hydrographs on all small watersheds?" They separated the hydrograph into "quickflow" and "delayed flow" components by arbitrarily projecting a line of constant slope from the beginning of any stream rise until it intersected the falling side of the hydrograph. The steady rise is described by the equations

$B_{t}=B_{t-1}+k$ for $Q_{t}>B_{t-1}+k$,

$B_{t}=Q_{t}$ for $Q_{t} \leq B_{t-1}+k$,

where $k$ is the slope of the dividing line. The slope they chose was $0.05 \mathrm{ft}^{3} \mathrm{~s}^{-1} \mathrm{mile}^{-2} \mathrm{~h}^{-1}\left(0.000546 \mathrm{~m}^{3} \mathrm{~s}^{-1} \mathrm{~km}^{-2} \mathrm{~h}^{-1}\right.$ or $0.0472 \mathrm{~mm} \mathrm{day}^{-1} \mathrm{~h}^{-1}$ ). This universal slope gives a firm basis for comparison of BFIs between catchments.

Tracer methods use dissolved chemicals and/or stable isotopes to separate the hydrograph into component hydrographs based on mass balance of water and tracers. Waters from different sources are assumed to have unique and constant (or varying in a well-understood way) compositions (Pinder and Jones, 1969; Sklash and Farvolden, 1979; McDonnell et al., 1991). These tracer methods allow for objective separation of the hydrograph, but it is important to consider just what water components are being separated. For example, deuterium varies much more in rainfall than it does
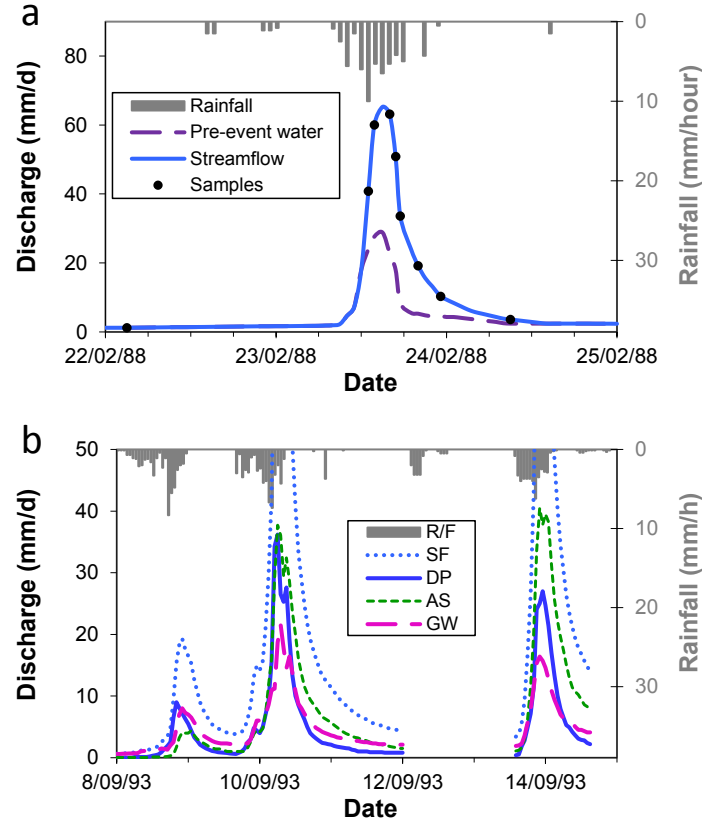

Figure 2. Tracer hydrograph separation results. (a) Event-pre-event water separation from catchment GH1, Glendhu, New Zealand, using deuterium (replotted from Bonell et al., 1990). (b) Threecomponent separation from Haute-Mentue research catchment, Switzerland, using silica and calcium (replotted from Iorgulescu et al., 2005). R/F is rainfall, SF is streamflow and the flow components are DP - direct precipitation, AS - acid soil and GW - groundwater.

in soil or groundwater, which has average deuterium concentrations from contributions from several past events. When the deuterium content of a particular rainfall is very high or very low, it becomes an effective indicator of the presence of "event" water in the stream, compared with the "preevent" water already in the catchment before rainfall began (as shown in Fig. 2a adapted from Bonell et al., 1990). Baseflow separations (i.e. identification of a groundwater component) have been more specifically shown by three-component separations using chemicals and stable isotopes (Bazemore et al., 1994; Hangen et al., 2001; Joerin et al., 2002; Iwagami et al., 2010). An example of separation of direct precipitation, acid soil and groundwater components using silica and calcium is given in Fig. 2b, redrawn from Iorgulescu et al. (2005).

A remarkable and by now well-accepted characteristic of these separations is that the components including groundwater often respond to rainfall as rapidly as the stream itself. Chapman and Maxwell (1996) noted that "hydrograph separation using tracers typically shows a highly responsive old flow". Likewise Wittenberg (1999) comments "tracers such as ${ }^{18} \mathrm{O} \ldots$ and salt ... [show] that even in flood periods outflow from the shallow groundwater is the major contributor to streamflow in many hydrological regimes". The first of Kirchner's (2003) streamflow paradoxes was described as 
"rapid mobilisation of old water" (which occurs during and after storm events). And Klaus and McDonnell (2013) observe "most [tracer studies] showed a large preponderance of pre-event water in the storm hydrograph, even at peak flow". This has been a general feature in tracer studies and includes all of the components tested whether quickflow or baseflow (e.g. Hooper and Shoemaker, 1986; Bonell et al., 1990; Buttle, 1994; Gonzales et al., 2009; Zhang et al., 2013). In the case of groundwater, the rapid response is believed to be partially due to rapid propagation of rainfall effects downwards (by pressure waves or celerity) causing rapid water table rise and displacement of stored water near the stream (e.g. Beven, 2012, p. 349; McDonnell and Beven, 2014; Stewart et al., 2007, p. 3354).

Chapman and Maxwell (1996) and Chapman (1999) compared baseflow separations based on digital filters (like the low-pass filters referred to above) with tracer separations in the literature and identified a preferred two-parameter algorithm given by

$B_{t}=\frac{m}{1+C} B_{t-1}+\frac{C}{1+C} Q_{t}$

which was able to approximately match the tracer separations. $m$ and $C$ are parameters identified by fitting to the pre-event hydrograph identified by tracers. Eckhardt (2005) demonstrated that some previously published digital filters (Lyne and Hollick, 1979; Chapman and Maxwell, 1996; Chapman, 1999) could be represented by a more general digital filter equation by assuming a linear relationship between baseflow and baseflow storage (see Eq. 9 below). Eckhardt's filter is

$B_{t}=\frac{\left(1-\mathrm{BFI}_{\max }\right) a B_{t-1}+(1-a) \mathrm{BFI}_{\max } Q_{t}}{1-a \mathrm{BFI}_{\max }}$,

where parameter $a$ is a recession constant relating adjacent baseflow steps during recessions; i.e.

$B_{t}=a B_{t-1}$

and is determined by recession analysis. On the other hand, there was no objective way to determine parameter $\mathrm{BFI}_{\max }$ (the maximum value of the baseflow index that can be modelled by the algorithm corresponding to low-pass filtering of a wave of infinite length). Eckhardt (2005) suggested that typical $\mathrm{BFI}_{\max }$ values can be found for classes of catchments based on their hydrological and hydrogeological characteristics (e.g. 0.8 for perennial streams in catchments with permeable bedrock). Eckhardt himself and others have pointed out that these $\mathrm{BFI}_{\max }$ values should be regarded as first approximations, and more refined values can be determined using tracers (Eckhardt, 2008; Gonzales et al., 2009; Zhang et al., 2013), by a backwards filtering operation (Collischonn and Fan, 2013) or by the relationship of two characteristic values from flow duration curves (i.e. $Q_{90} / Q_{50}$, Smakhtin, 2001; Collischonn and Fan, 2013).

\section{The new baseflow separation method}

The new baseflow separation method put forward in this paper (BRM) has an algorithm chosen specifically to simulate tracer separations. Tracer separations show rapid baseflow responses to storm events (the "bump"), which is followed in the method by a steady rise in the sense of Hewlett and Hibbert (1967) (the "rise"). The steady rise is justified by increase in catchment wetness conditions and gradual replenishment of groundwater aquifers during rainy periods. The size of the bump $(f)$ and the slope of the rise $(k)$ are parameters of the recursive digital filter that can be applied to the streamflow record. The separation procedure is described by the equations

$$
\begin{aligned}
& B_{t}=B_{t-1}+k+f\left(Q_{t}-Q_{t-1}\right) \text { for } Q_{t}>B_{t-1}+k, \\
& B_{t}=Q_{t} \text { for } Q_{t} \leq B_{t-1}+k,
\end{aligned}
$$

where $f$ is a constant fraction of the increase or decrease of streamflow during an event. The values of $f$ and $k$ can be determined from tracer measurements, like the parameters of other digital filters. If no tracer information is available, $f$ and $k$ can be determined by an optimisation process as described in an earlier version of this paper (Stewart, 2014a). A particular feature of the BRM method is that two types of baseflow response are included, a short-term response via the bump and a longer-term response via the rise.

\subsection{Recession analysis}

Recession analysis also has a long history. Stoelzle et al. (2013) recently highlighted discrepancies between methods of extracting recession parameters from empirical data by contrasting results from three established methods (Brutsaert and Nieber, 1977; Vogel and Kroll, 1992; Kirchner, 2009). They questioned whether such parameters are really able to characterise catchments to assist modelling and regionalisation, and suggested that researchers should use more than one method because specific catchment characteristics derived by the different recession analysis methods were so different.

The issue of whether storages can be represented by linear reservoirs or require to be treated as non-linear reservoirs has also been widely discussed in the hydrological literature (in the case of recession analysis by Brutsaert and Nieber, 1977, Tallaksen, 1995, Lamb and Beven, 1997 and Fenicia et al., 2006, among others). Lamb and Beven (1997) identified three different storage behaviours in the three catchments they studied. Linear reservoirs only require one parameter each and are more tractable mathematically. They are widely used in rainfall-runoff models. Non-linearity can be approximately accommodated by using two or more linear reservoirs in parallel, but more parameters are required (three in the case of two reservoirs). Linear storage is expressed by the formulation 
$V=Q / \beta$,

where $V$ is storage volume, and $\beta$ is a constant (with dimensions of $\mathrm{T}^{-1}$ ). The exponential relationship follows for baseflow recessions

$Q_{t}=Q_{o} \exp (-\beta t)$

where $Q_{o}$ is the streamflow at the beginning of the recession.

However, evidence for non-linearity is strong (Wittenberg, 1999) and the non-linear formulation is often used

$V=e Q^{b}$,

where $e$ and $b$ are constants. This gives the recession equation

$Q_{t}=Q_{o}\left[1+\frac{(1-b) Q_{o}^{(1-b)}}{e b} t\right]^{1 /(b-1)}$.

The exponent $b$ has been found to take various values between 0 and 1.1, with an average close to 0.5 (Wittenberg, 1999); $b=1$ gives the linear storage model (Eqs. 9 and 10). For $b=0.5$, Eq. (11) reduces to the quadratic equation

$Q_{t}=Q_{o}\left[1+\frac{1}{a e} \cdot Q_{o}^{0.5} \cdot t\right]^{-2}$.

This quadratic equation is similar to the equation derived much earlier by Boussinesq (1903) as an analytical solution for drainage of a homogeneous groundwater aquifer limited by an impermeable horizontal layer at the level of the outlet to the stream

$Q_{t}=Q_{o}(1+\alpha t)^{-2}$,

where $\alpha$ is

$\alpha=K B / P L^{2}$.

Here $K$ is the hydraulic conductivity, $P$ the effective porosity, $B$ the effective aquifer thickness, and $L$ the length of the flow path. Dewandel et al. (2003) have commented that only this quadratic form is likely to give correct values for the aquifer properties because it is an exact analytical solution to the diffusion equation, albeit with simplifying assumptions, whereas other forms (e.g. exponential) are approximations.

In order to generalise recession analysis for a stream (i.e. to be able to analyse the stream's recessions collectively rather than individually), Brutsaert and Nieber (1977) presented a method based on the power-law storage-outflow model, which describes flow from an unconfined aquifer into a stream. The negative gradient of the discharge (i.e. the slope of the recession curve) is plotted against the discharge, thereby eliminating time as a reference. This is called a recession plot below (following Kirchner, 2009).
To keep the timing right, the method pairs streamflow $Q=\left(Q_{t-1}+Q_{t}\right) / 2$ with a negative streamflow recession rate $-\mathrm{d} Q / \mathrm{d} t=Q_{t}-Q_{t-1}$.

Change of storage in the catchment is given by the water balance equation

$\frac{\mathrm{d} V}{\mathrm{~d} t}=R-E-Q$,

where $R$ is rainfall and $E$ is evapotranspiration. Assuming no recharge or extraction, we have

$\frac{\mathrm{d} V}{\mathrm{~d} t}=-Q$

from where Eq. (11) leads to

$-\frac{\mathrm{d} Q}{\mathrm{~d} t}=\frac{1}{e b} Q^{2-b}=c Q^{d}$.

The exponent $d$ allows for both linear $(d=1)$ and non-linear $(d \neq 1)$ storage-outflow relationships, with $d=1.5$ giving the frequently observed quadratic relationship (Eq. 13). Authors who have investigated the dependence of $-\mathrm{d} Q / \mathrm{d} t$ on $Q$ for late recessions (low flows) have often found $d$ averaging close to 1.5 (e.g. Brutsaert and Nieber, 1977; Wittenberg, 1999; Dewandel et al., 2003; Stoelzle et al., 2013). Higher values of $d$ were often found especially at higher flows; e.g. Brutsaert and Nieber (1977) found values of $d=3$ for the early parts of recessions.

Recent work has continued to explore the application and possible shortcomings of the recession plot method. Rupp and Selker (2006) proposed scaling of the time increment to the flow increment which can greatly reduce noise and artefacts in the low-flow part of the plot. Biswal and Marani (2010) identified a link between recession curve properties and river network morphology. They found slopes of individual recession events in recession plots ( $d$ values) averaging around 2 and ranging from 1.1 to 5.5. In a small $\left(1 \mathrm{~km}^{2}\right)$ catchment, McMillan et al. (2011) showed that individual recessions plotted on the recession plot "shifted horizontally with season", which they attributed to changes in contributing subsurface reservoirs as streamflow levels changed with season. This explanation is analogous to the approach below in that two water components with different storage characteristics are implied. The slopes of individual recessions in their analysis were in excess of 2 with the low-flow tails being very much steeper. In medium to large catchments $\left(100-6414 \mathrm{~km}^{2}\right)$, Shaw and Riha (2012) found curves of individual recessions "shifted upwards in summer relative to early spring and late fall curves", producing a data cloud when recessions from all seasons were combined. They speculate that the movement with season (which was similar, but less extreme to that seen by McMillan et al. (2011) above) was due to seasonal changes of catchment evapotranspiration. They found that the slopes of individual recessions were often close to 2 and had an extreme range of 1.3 to 5.3 . 
Problems in determining recession-parameter values from streamflow data on recession plots are due to (1) different recession extraction methods (e.g. different selection criteria for data points) and (2) different parameter-fitting methods to the power-law storage-outflow model (Eq. 18). There is generally a very broad scatter of points on the plots, which makes parameter fitting difficult. Clearly evapotranspiration is likely to play a role in producing some of the scatter because evapotranspiration was neglected from Eq. (16). However, it is also believed that part of the scatter is due to recession analysis being applied to streamflow rather than to its separated components (see below).

\section{The new recession analysis approach}

The new approach proposed here consists of applying recession analysis via the recession plot to separated quickflow and baseflow components as well as to the streamflow. The rationale for this is that quickflow and baseflow are derived from different storages within the catchment. In particular, the changing proportions of quickflow and baseflow in streamflow during early parts of recessions cause recession analyses of streamflow to give mixed messages, i.e. misleading results not characteristic of storages in the catchment, as demonstrated for Glendhu Catchment below. This is expected to have led to some previous recession analysis studies giving misleading results in regard to catchment storage in cases where early recession streamflow has been analysed.

\subsection{Flow duration curves}

Flow duration curves (FDCs) represent in one figure the flow characteristics of a stream throughout its range of variation. They are cumulative frequency curves that show the percentages of time during which specified discharges were equalled or exceeded in given periods. They are useful for practical hydrology (Searcy, 1959), and have been used as calibration targets for hydrologic models (Westerberg et al., 2011).

FDCs can also be determined for the separated stream components as shown below (Fig. 5d). Although FDCs for streamflow are not misleading and obviously useful in their own right, FDCs of separated components can give insight into the processes of streamflow generation at each exceedance percentage.

\subsection{Hydrogeology of Glendhu Catchment}

Glendhu GH1 Catchment $\left(2.18 \mathrm{~km}^{2}\right)$ is situated $50 \mathrm{~km}$ inland from Dunedin in the South Island of New Zealand. It displays rolling-to-steep topography and elevation ranges from 460 to 650 ma.s.l. (Fig. 3). Bedrock is moderately to strongly weathered schist, with the weathered material filling in pre-existing gullies and depressions. Much of the bedrock-colluvial surface is overlain by a loess mantle of variable thickness $(0.5$ to $3 \mathrm{~m})$. Well-to-poorly drained silt

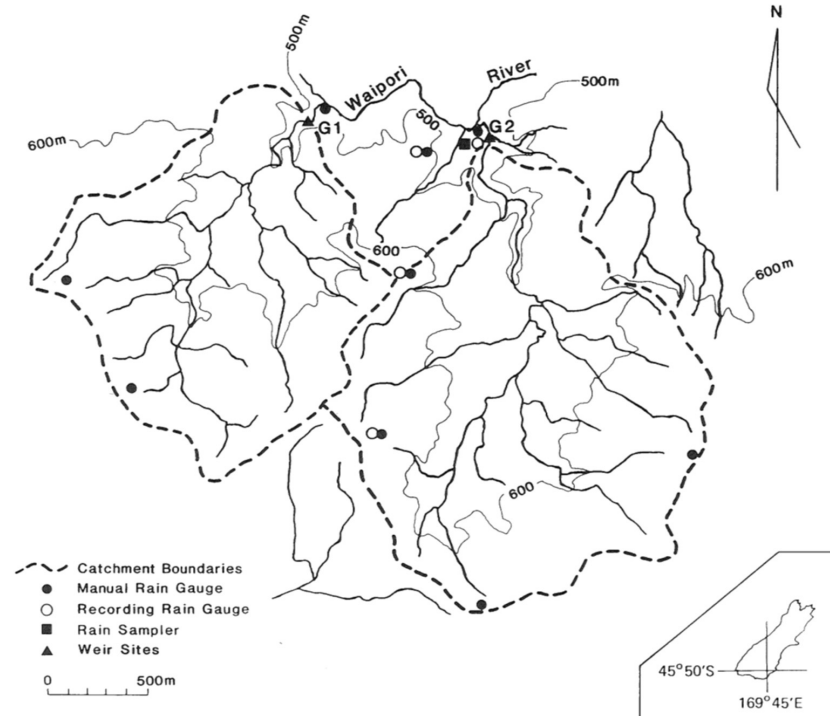

Figure 3. Map of Glendhu Catchments (GH1 and GH2). The inset shows their location in the South Island of New Zealand.

loams are found on the broad interfluves and steep side slopes, and poorly drained peaty soils in the valley bottoms.

Amphitheatre-like sub-catchments are common features in the headwaters and frequently exhibit central wetlands that extend downstream as riparian bogs. Snow tussock (Chionochloa rigida) is the dominant vegetation cover and headwater wetlands have a mixed cover of sphagnum moss, tussock and wire grass (Empodisma minus). The mean annual temperature within $\mathrm{GH} 1$ at $625 \mathrm{~m}$ a.s.l. is $7.6^{\circ} \mathrm{C}$, and the mean annual rainfall is $1350 \mathrm{~mm} / \mathrm{a}$. Annual runoff is measured at all weirs to an accuracy of $\pm 5 \%$ (Pearce et al., 1984).

Pearce et al. (1984) showed that GH1 and GH2 (before the latter was forested) had very similar runoff ratios. Longterm precipitation and runoff at GH1 weir average 1350 and $743 \mathrm{~mm} \mathrm{a}^{-1}$, respectively (Fahey and Jackson, 1997). Actual evapotranspiration of $622 \mathrm{~mm} \mathrm{a}^{-1}$ was measured for tussock grassland in the period April 1985 to March 1986 at a nearby site in catchment GH1 (570 ma.s.l.) by Campbell and Murray (1990) using a weighing lysimeter. The Priestley-Taylor estimate of PET was $643 \mathrm{~mm} \mathrm{a}^{-1}$ for the period, and $599 \mathrm{~mm} \mathrm{a}^{-1}$ for 1996, so ET for GH1 is taken as $600 \mathrm{~mm} \mathrm{a}^{-1}$. The GH1 hydrological balance is precipitation $\left(1350 \mathrm{~mm} \mathrm{a}^{-1}\right)-$ ET $\left(600 \mathrm{~mm} \mathrm{a}^{-1}\right)=$ runoff $\left(743 \mathrm{~mm} \mathrm{a}^{-1}\right)$, and loss around the weir is clearly negligible (Pearce et al., 1984). Comparison of runoff in GH1 and GH2 (after the latter had been forested for 7 years) showed that there was a decrease of $260 \mathrm{~mm} \mathrm{a}^{-1}$ in GH2 runoff due to afforestation (Fahey and Jackson, 1997). Consequently, the GH2 balance is precipitation $\left(1350 \mathrm{~mm} \mathrm{a}^{-1}\right)-\mathrm{ET}\left(860 \mathrm{~mm} \mathrm{a}^{-1}\right)=$ runoff $\left(483 \mathrm{~mm} \mathrm{a}^{-1}\right)$. The increase in ET for GH2 is attributed to increased interception (with evaporative loss) and transpiration. 
Bonell et al. (1990) carried out separation of event and pre-event waters using deuterium and chloride concentrations to investigate the runoff mechanisms operating in GH1 and GH2 at Glendhu (see example in Fig. 2a). The results showed that for quickflow volumes greater than $10 \mathrm{~mm}$ (over the catchment area), the early part of the storm hydrograph could be separated into two components, pre-event water from a shallow unconfined groundwater aquifer, and event water attributed to "saturated overland flow". The pre-event water responded more rapidly to rainfall than event water. The late part of the storm hydrograph consisted of pre-event water only. Hydrographs for smaller storms had pre-event water only, but this may be partly because measurement accuracy of the deuterium may not have been sufficient to detect event water in these smaller events.

Quickflow at Glendhu comprises event water plus rapidly mobilised soil water (e.g. Bowden et al., 2001; Stewart, 2014a), while baseflow has young (from weathered colluvium and loess) and old (schist bedrock) groundwater components as shown by tritium measurements (Stewart and Fahey, 2010).

\section{Results of application of new approaches to Glendhu GH1 Catchment}

The BRM baseflow separation method is applied to Glendhu GH1 Catchment to investigate its applicability, demonstrate how it is applied and present what it reveals about the catchment. The results are compared with those from two other widely used baseflow separation filters, the Hewlett and Hibbert (1965) method (called the H \& H method below) and the Eckhardt (2005) method (called the Eckhardt method below). We need to know the values of the parameters of these methods in order to apply them, the parameters are $k$ (the universal slope of the rise through the event) for the $\mathrm{H} \& \mathrm{H}$ method, $\mathrm{BFI}_{\max }$ (the maximum value of the baseflow index that can be modelled by the Eckhardt algorithm) and a recession constant for the Eckhardt method, and $f$ (bump fraction) and $k$ (slope of the rise) for the BRM method.

The parameter $k$ for the $\mathrm{H} \& \mathrm{H}$ method has the universal (arbitrary) value of $0.0472 \mathrm{~mm} \mathrm{day}^{-1} \mathrm{~h}^{-1}$, as explained above. Estimation of the Eckhardt parameters is not so simple (see above) and has similarities to the estimation of the BRM parameters. There are two ways of determining the Eckhardt and BRM parameters: (1) by adjusting the baseflow parameters to give the best fits between the baseflows and the tracer-determined pre-event or baseflow water. This is regarded as the only objective way, and is able to be used in this paper because deuterium data is available for Glendhu (Bonell et al., 1990). But it requires tracer data during events which is not generally available for catchments. (2) Where there is no tracer data, the parameters can be estimated in several ways. In the prescribed Eckhardt method, $a$ is calculated from the late part of the recession by an objective procedure. $\mathrm{BFI}_{\max }$ is estimated to a first approximation based on the hydrological and hydrogeological characteristics of the catchment (Eckhardt, 2005), and possibly more precisely by hydrograph methods suggested by Collischonn and Fan (2013) (see Sect. 3.1). For the BRM, the BFI can be estimated approximately from catchment considerations (in analogy with the Eckhardt method) and possibly more precisely by a flow duration curve method suggested by Collischonn and Fan (2013). The BFI can then be used as a constraint while optimising the fit between the sum and the streamflow (where the sum equals the baseflow plus a fast recession). This optimising procedure was used in the earlier version of this paper (Stewart, 2014a). The optimising procedure was also applied to the $\mathrm{H} \& \mathrm{H}$ and Eckhardt methods in the author's reply (Stewart, 2014b).

Once baseflow separation has been achieved, recession analysis via the recession plot can be applied to the separated quickflow and baseflow components (the new approach suggested here), in addition to the streamflow (the traditional method). Whereas the streamflow can show high powerlaw slopes ( $d$ values of 2 or more), the components generally have slopes around 1.5. However, note that in the early part of the recession the baseflow is a subdued reflection of the streamflow because of its calculation procedure (Eqs. 7 and 8), while in the late part of the recession the baseflow and the streamflow are the same. Flow duration curve analysis can also be applied to the components as well as to the streamflow in order to show the make-up of the streamflow at each exceedance percentage.

\subsection{Application of baseflow separation methods}

Figure 2a showed the pre-event component determined using deuterium during a large storm on 23 February 1988 (Bonell et al., 1990). The pre-event component has a BFI of 0.529 during the event (Table 1). Baseflows determined by the three baseflow separation methods are compared with the pre-event component in Fig. 4a-c. The goodness of fit of the baseflows to the pre-event water was determined using least squares:

$\mathrm{SD}=\left(\sum\left(B_{i}-\mathrm{PE}_{i}\right)^{2} / N\right)^{0.5}$,

where $\mathrm{PE}_{i}$ is the pre-event water at each time step, and $N$ the number of values. The $\mathrm{H} \& \mathrm{H}$ baseflow is totally inflexible with a pre-determined parameter and does not match the BFI or shape of the pre-event hydrograph at all well (its BFI is 0.255 and $\mathrm{SD}$ is $6.41 \mathrm{~mm}$ day $^{-1}$; Table 1; Fig. 4a).

The Eckhardt baseflow with prescribed parameters $\left(\mathrm{BFI}_{\max }=0.8\right.$ for a porous perennial stream, and $a=0.99817$ calculated from the baseflow recession) does not match the pre-event hydrograph well either $(\mathrm{BFI}=0.272$, $\mathrm{SD}=6.34 \mathrm{~mm} \mathrm{day}^{-1}$; Fig. $4 \mathrm{c}$ ). However, a better match of the BFI and a slightly better fit is found with the optimized 
Table 1. Tracer calibration of the baseflow separation methods by comparison with pre-event water determined using deuterium for a streamflow event on 23 February 1988 at Glendhu GH1 Catchment (Bonell et al., 1990). The listed parameters were determined as described in the text. The standard deviations (SD) show the goodness of fit between the various baseflows and the pre-event water.

\begin{tabular}{lcclllc}
\hline $\begin{array}{l}\text { Separation } \\
\text { method }\end{array}$ & $\mathrm{BFI}^{*}$ & $f^{*}$ & $\begin{array}{l}k^{*} \\
\mathrm{~mm} \mathrm{day}^{-1} \mathrm{~h}^{-1}\end{array}$ & $\mathrm{BFI}_{\max }^{*}$ & $\begin{array}{l}a^{*} \\
\mathrm{~h}^{-1}\end{array}$ & $\begin{array}{c}\mathrm{SD} \\
\mathrm{mm} \mathrm{day}^{-1}\end{array}$ \\
\hline Pre-event water & 0.529 & - & - & - & - & - \\
H \& H & 0.255 & - & 0.0472 & - & - & 6.41 \\
Eckhardt (prescribed) & 0.272 & - & - & 0.8 & 0.9982 & 6.34 \\
Eckhardt (optimized) & 0.524 & - & - & 0.886 & 0.991 & 5.40 \\
BRM & 0.526 & 0.40 & 0.009 & - & - & 1.98 \\
\hline
\end{tabular}

* BFI is baseflow index, $f$ is bump fraction, $k$ is slope parameter, $\mathrm{BFI}_{\max }$ is the maximum value of the baseflow index that can be modelled by the Eckhardt algorithm and $a$ is the recession constant.
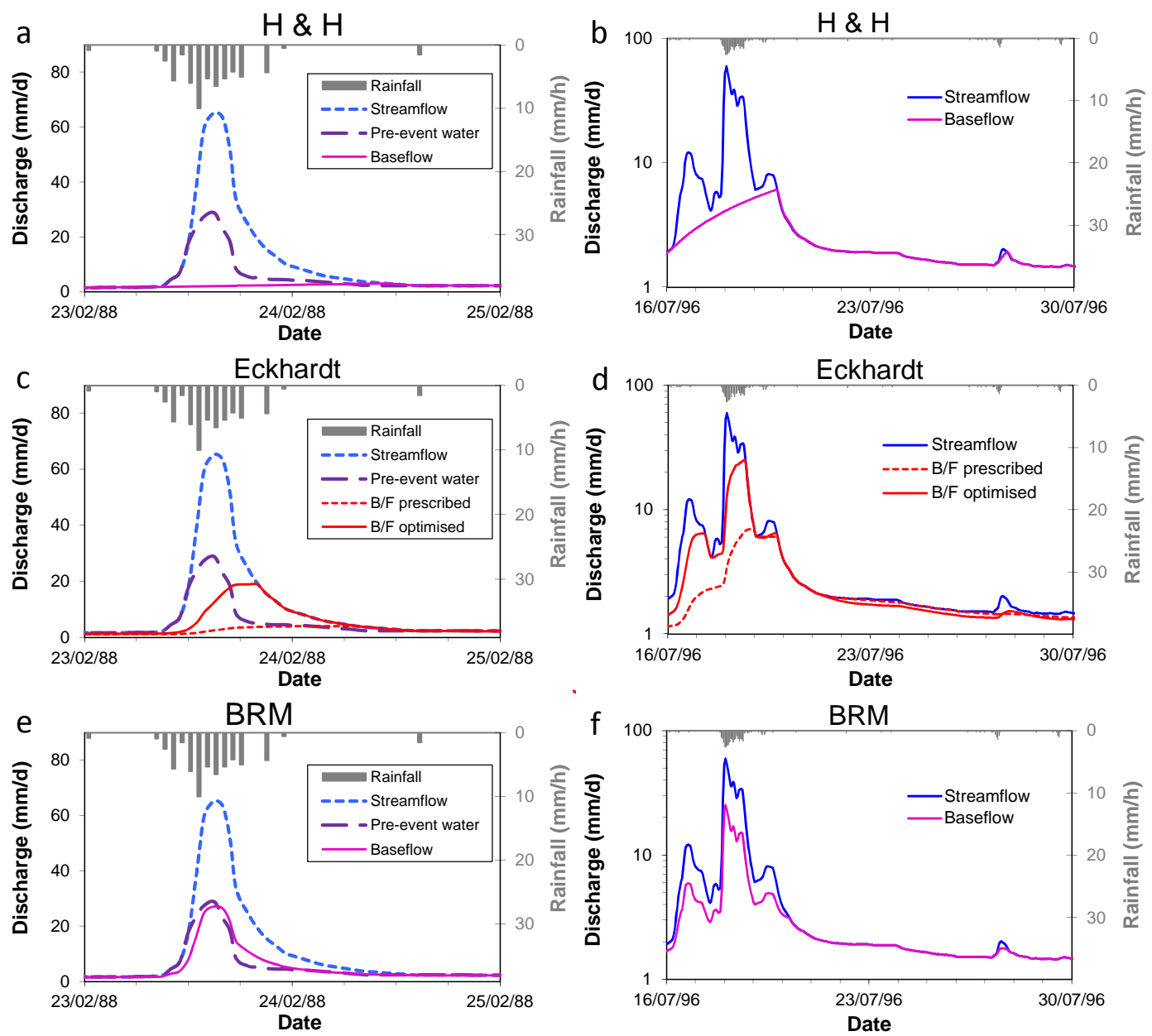

Figure 4. (a, c, e) Application of the three baseflow separation methods to fit the pre-event component determined by deuterium measurements at Glendhu GH1 Catchment for an event on 23 February 1988. The parameters determined by fitting are given in Table 2; (b, d, f) Baseflows resulting from the best-fit parameters for a 2-week period in 1996; note the logarithmic scales.

version when both $\mathrm{BFI}_{\max }$ and a are treated as adjustable parameters using the method of Zhang et al., 2013 (i.e. BFI $_{\max }$ was adjusted first to match the Eckhardt BFI to the pre-event BFI, then $a$ was adjusted to improve the fit between the shapes of the baseflow and the pre-event hydrographs, then the steps were repeated). An extra constraint was to prevent the Eckhardt baseflow falling too far below the streamflow at very low flows. These give a BFI of 0.524 , which is the same as that of the pre-event hydrograph $(0.529$, Table 1$)$, and the baseflow has a similar shape to the pre-event water 
(Fig. 4c), but the peak is delayed in time giving only a small improvement in the fit $\left(\mathrm{SD}=5.40 \mathrm{~mm} \mathrm{day}^{-1}\right)$.

The BRM baseflow gives a BFI of 0.526, the same as that of the pre-event hydrograph, and the fit between the two hydrographs is very close $\left(\mathrm{SD}=1.98 \mathrm{~mm} \mathrm{day}^{-1}\right.$; Fig. $\left.4 \mathrm{e}\right)$. This reflects the choice of the algorithm to mimic tracer baseflow separations (Eqs. 7 and 8), which it does very well.

The three methods have been applied to hourly streamflow data for 1996. A sample of each is shown for a 2-week period in Fig. 4b, $d$ and f. Only this short period is shown because otherwise it is difficult to see the baseflow clearly. The parameters used are listed in Table 2 along with the annual $\mathrm{BFI}$ values determined. The $\mathrm{H} \& \mathrm{H}$ baseflow rises gradually through the stormflow peak, then follows the falling limb of the streamflow after it intersects with it. The prescribed Eckhardt baseflow also rises gradually through the peak then stays close to the recessing streamflow. The optimized Eckhardt baseflow rises sharply then falls sharply when it intersects the falling limb of the streamflow, and then gradually falls below the recessing streamflow curve. The BRM baseflow mirrors the streamflow peak then follows the falling streamflow after it intersects with it. It is also instructive to compare the BFI values derived by the various methods. The $\mathrm{H} \& \mathrm{H}$ method gives a BFI of 0.679 , the Eckhardt methods BFIs of 0.617 and 0.754 and the BRM method a BFI of 0.780 (almost the same as the $Q_{90} / Q_{50}$-derived BFI of 0.779 ; see this section below).

Table 2 also shows estimates based on the characteristic flows from the flow duration curve $\left(Q_{90} / Q_{50}\right)$. Smakhtin (2001) observed that the ratio of the two characteristic flows could be used to estimate BFI, and Collischonn and Fan (2013) derived equations connecting $Q_{90} / Q_{50}$ and $\mathrm{BFI}_{\max }$ and BFI based on results from 15 catchments of varying sizes in Brazil. Their equations were

$\mathrm{BFI}_{\text {max }}=0.832 \frac{Q_{90}}{Q_{50}}+0.216$,

$\mathrm{BFI}=0.850 \frac{Q_{90}}{Q_{50}}+0.163$.

These have been used to determine BFImax and BFI in Table 2 (marked as FDC BFI $_{\max }$ and FDC BFI for clarity) for comparison with those derived using the three baseflow separation methods. There is a close correspondence between the FDC BFI and the BRM BFI, as noted, but the others are not particularly close. The backwards filter method of Collischonn and Fan (2013) has also been applied to estimate the $\mathrm{BFI}_{\max }$ values for the prescribed and optimized Eckhardt parameters (Table 2). The resulting BFIs do not agree particularly well with the BFIs obtained from the other methods.

The second way of determining the BRM parameters was described in the earlier version of this paper (Stewart, 2014a). Streamflow data was available for a summer month (February 1996) and a winter month (August 1996). These had different BFIs, but the bump fractions $(f)$ obtained by finding the best-fits of the sum (i.e. baseflow plus fast recession) to the streamflow were similar at 0.16 , while the slopes $(k)$ were different. The fast recession was assumed to have a quadratic form (i.e. $d=1.5$, Eq. 14) when fitting the sum to the streamflow, but the exponential $(d=1)$ and reciprocal $(d=2)$ forms were also tested and found to give the same quadratic result for the quickflow (i.e. slope of $d=1.5$ on Fig. 5c) (Stewart, 2014a). This optimising process was also applied to the Eckhardt method in Stewart (2014b).

\subsection{Application of new approach to recession and flow duration curve analysis}

The recession behaviour of the streamflow, BRM baseflow and BRM quickflow from the hourly streamflow record during 1996 are examined on recession plots (i.e. $-\mathrm{d} Q / \mathrm{d} t$ versus $Q$ ) in Fig. 5a-c. Discharge data less than $2 \mathrm{~h}$ after rainfall has been excluded. The three figures have the same two lines on each. The first is a line through the lower part of the streamflow data with slope of 6 (this is called the streamflow line; see Fig. 5a). The second is a line through the quickflow points with slope of about 1.5 (this is called the quickflow line; see Fig. 5c). The streamflow points define a curve approaching the quickflow line at high flows when baseflow makes up only a small proportion of the streamflow, and diverging from it when baseflow becomes more important. The slope of a line through the points is much steeper in this lower portion (as shown by the streamflow line). The baseflow points (Fig. 5b) have a similar pattern to the streamflow points because the BRM baseflow shape mimics the streamflow shape at high to medium flows because of the form of Eqs. (7) and (8). At low flows the baseflow plots on the streamflow and hence shows the same low-flow pattern as the streamflow.

Quickflow is determined by subtracting baseflow from streamflow (Eq. 1). It rises rapidly from 0 or near-zero at the onset of rainfall to a peak $2-3 \mathrm{~h}$ after rainfall, then falls back to 0 in around 24 to $48 \mathrm{~h}$ unless there is further rain. The quickflow points at flows above about $1 \mathrm{~mm} \mathrm{day}^{-1}$ fall on the quickflow line with slope of 1.5. Errors become much larger as quickflow becomes very small (i.e. as baseflow approaches streamflow when quickflow is the small difference between the two). As Rupp and Selker (2006) have noted "time derivatives of $Q$ amplify noise and inaccuracies in discharge data". Nevertheless the quickflow points show a clear pattern supporting near-quadratic fast recessions. The streamflow points might be expected to show a recession slope of 1.5 at very low flows as the streamflow becomes dominated by baseflow, but the data may not be accurate enough to show this (see Sect. 3.4).

Flow duration curves for streamflow, baseflow and quickflow are given in Fig. 5d. The streamflow FDC has a very shallow slope indicating groundwater dominance over the higher exceedance percentages. Streamflow diverges noticeably from baseflow below about $17 \%$ exceedance (when 
Table 2. BFIs and parameters of the baseflow separation methods applied to the hourly streamflow record in 1996, and to the master recession curve. The $Q_{90} / Q_{50}$ ratio is from the flow duration curve for 1996, and the FDC $\mathrm{BFI}_{\max }$ and FDC BFI are from Eqs. (20) and (21) in the text.

\begin{tabular}{|c|c|c|c|c|c|}
\hline $\begin{array}{l}\text { Separation } \\
\text { method }\end{array}$ & $\mathrm{BFI}^{*}$ & $f^{*}$ & $\begin{array}{l}k^{*} \\
\mathrm{~mm} \text { day }^{-1} \mathrm{~h}^{-1}\end{array}$ & $\mathrm{BFI}_{\max }^{*}$ & $\begin{array}{l}a^{*} \\
\mathrm{~h}^{-1}\end{array}$ \\
\hline$Q_{90} / Q_{50}$ & 0.728 & - & - & - & - \\
\hline $\mathrm{FDC} \mathrm{BFI}_{\max }$ (Eq. 20) & - & - & - & 0.824 & - \\
\hline FDC BFI (Eq. 21) & 0.779 & - & - & - & - \\
\hline $\mathrm{H} \& \mathrm{H}$ & 0.679 & - & 0.0472 & - & - \\
\hline Eckhardt (prescribed) & 0.617 & - & - & 0.8 & 0.9982 \\
\hline Eckhardt (back filter) & 0.521 & - & - & 0.593 & 0.9982 \\
\hline Eckhardt (optimized) & 0.754 & - & - & 0.886 & 0.991 \\
\hline Eckhardt (back filter) & 0.580 & - & - & 0.668 & 0.991 \\
\hline $\mathrm{BRM}$ & 0.780 & 0.40 & 0.009 & - & - \\
\hline Master recession curve & 0.828 & 0.40 & 0.009 & - & - \\
\hline
\end{tabular}

* BFI is baseflow index, $f$ is bump fraction, $k$ is slope parameter, $\mathrm{BFI}_{\max }$ is the maximum value of the baseflow index that can be modelled by the Eckhardt algorithm and $a$ is the recession constant.
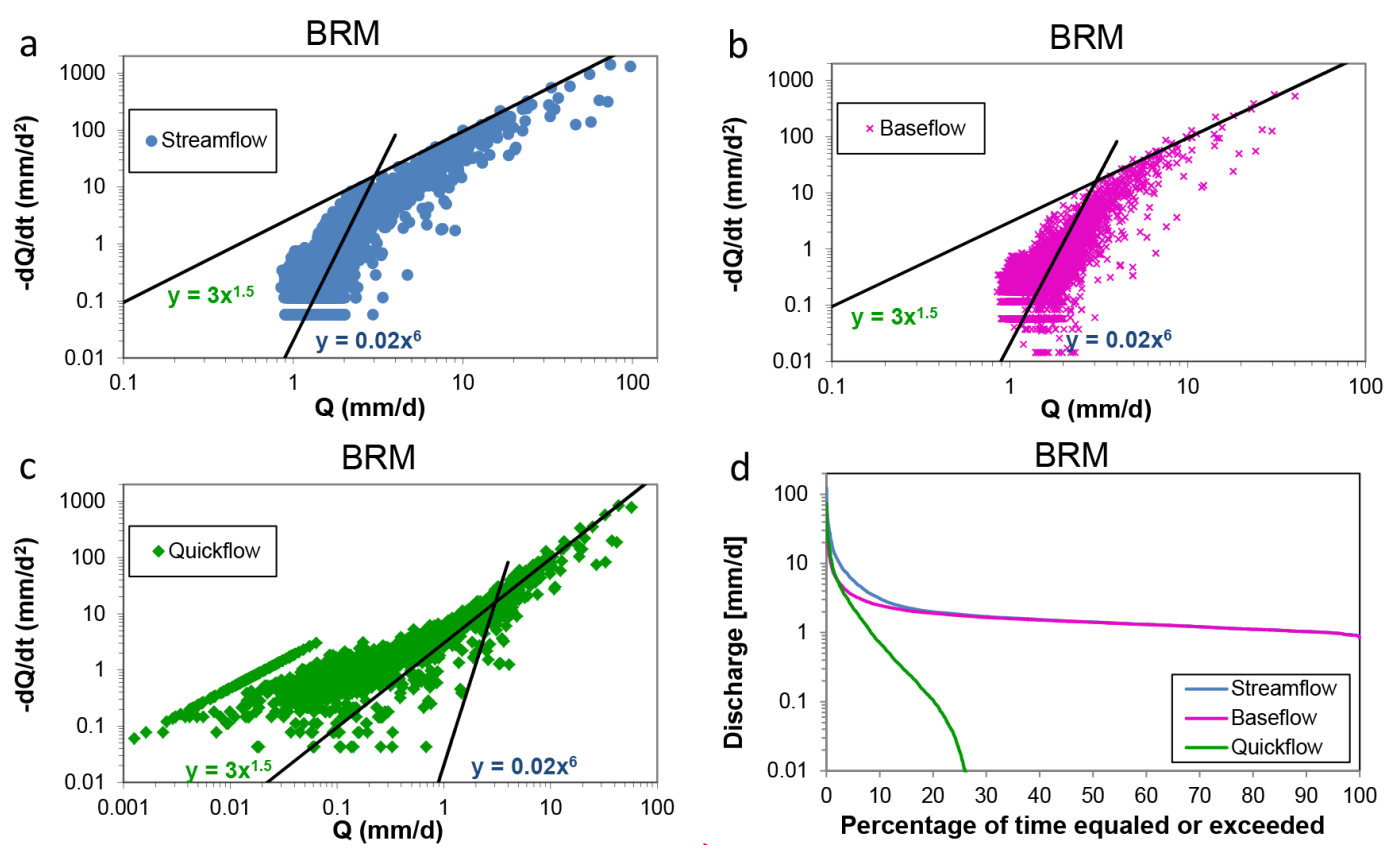

Figure 5. (a-c) Recession plots showing streamflow, baseflow and quickflow from the 1996 GH1 hourly flow record. The line through the mid-flow streamflow and baseflow points has slope of 6.0, and that through the higher flow quickflow points (flows greater than $1 \mathrm{~mm}^{-1 a y}{ }^{-1}$ ) has slope of 1.5; (d) flow duration curve showing streamflow, baseflow and quickflow.

quickflow reaches about $10 \%$ of streamflow). Note that the temporal connection between the streamflow and components is not the same, each has been sorted separately to produce the relevant FDC. The figure reveals the reasons for breakpoints (i.e. changes of slope) in streamflow FDCs, which have been related to contributions from different sources/reservoirs in catchments (e.g. Pfister et al., 2014).

\section{3 "Master" recession curve for Glendhu}

Figure $6 a$ shows the master recession curve not involving snowmelt or additional rainfall, derived by Pearce et al. (1984) from the longest recessions observed during a 3 year study period in GH1 and GH2 (before afforestation of $\mathrm{GH} 2$ ). The data for the curve come from four storm events during winter and six during summer. These authors reported that "This recession curve is typical of high to medium runoff events. The plot shows that there is a marked change of slope between the early and late parts of the recessions (at a flow 

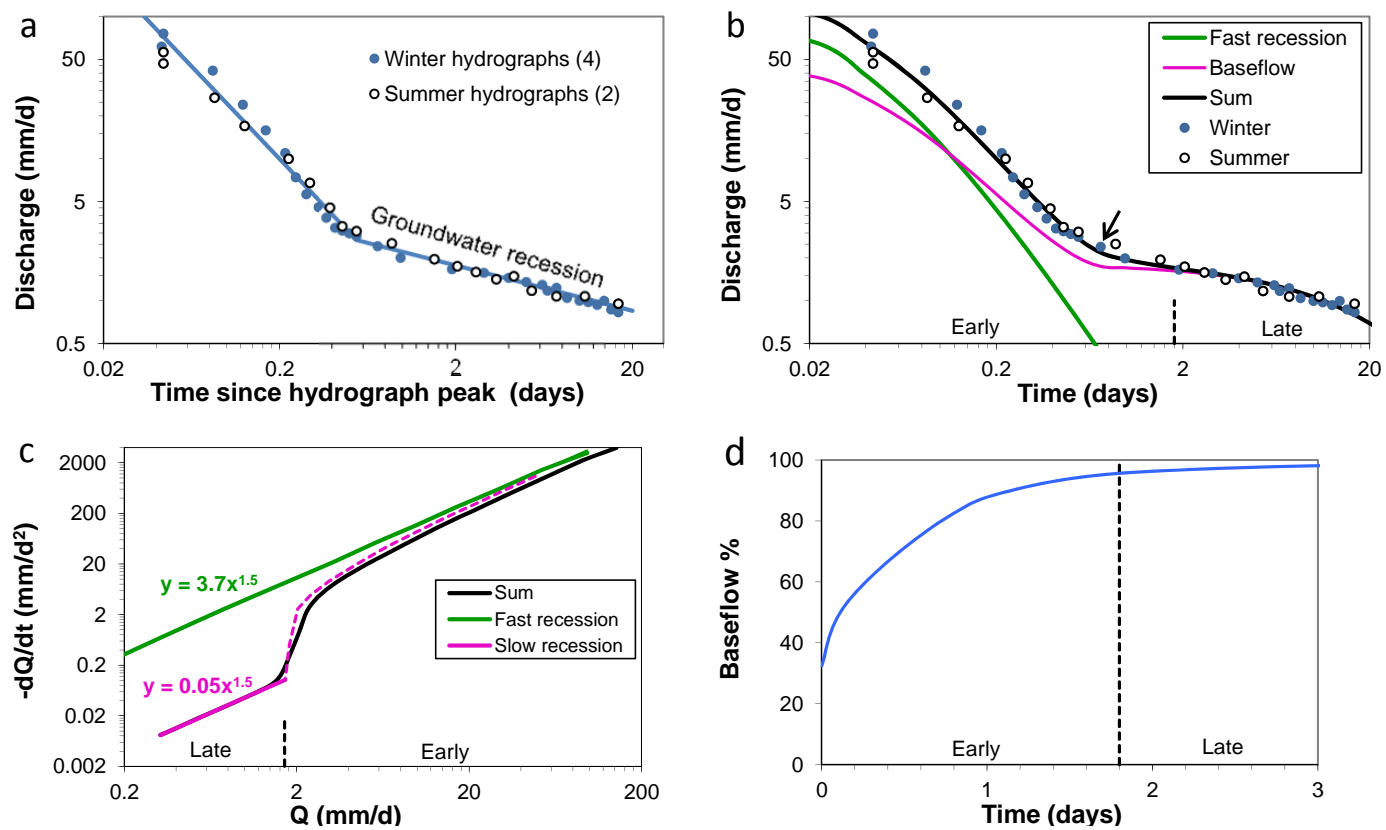

Figure 6. (a) "Master" recession curve for Glendhu GH1 Catchment (redrawn from Pearce et al., 1984). (b) Master recession data matched by the sum of the baseflow and a fast recession curve. The arrow shows the inflexion point. Early and late parts of the master recession curve are shown. (c) Recession plot of master recession curve (sum), baseflow and fast recession. The sum is close to the fast recession curve at high flows and close to the baseflow (slow recession curve) at low flows. The dashed part of the curve shows the "bump" in the baseflow; (d) variation of the baseflow contribution to streamflow with time during the master recession curve.

of about $\left.2.6 \mathrm{~mm} \mathrm{day}^{-1}\right)$. Quickflow, as defined by the method of Hewlett and Hibbert (1967), comprises $30 \%$ of the annual hydrograph and ceases shortly after the change in recession rate in most hydrographs."

The streamflow points from the master curve have been fitted by the sum of a quadratic fast recession curve and the baseflow (Fig. 6b). The baseflow was calculated using the parameters identified by the fitting to the pre-event hydrograph above ( $f=0.40 ; k=0.009 \mathrm{~mm} \mathrm{day}^{-1} \mathrm{~h}^{-1}$; Table 2$)$. These parameters give a BFI of 0.828. During the late part of the recession, when the baseflow dominates the streamflow, a slow recession curve was fitted to the streamflow. The data are given in Table 2. The sum fits all of the points well and there is a smooth transition between the early and late parts of the recession. The inflexion point (Fig. 7b) occurs when the baseflow stops falling and begins to rise. The inflexion point is therefore an expression of the change from the bump to the rise in the baseflow and supports the BRM baseflow separation method. The change from early to late recession when baseflow begins to dominate the recession comes considerably after the inflexion point (Fig. 6b).

It is also instructive to see the recession plot of the data (Fig. 6c). The quickflow (i.e. fast) and baseflow (i.e. slow) recessions are shown, both with slopes of 1.5 . The early part of the baseflow (i.e. the bump) is shown by the dashed curve. The sum of the fast recession and the baseflow, which fits the streamflow points, is close to the fast recession at high flow and matches the slow flow recession at low flows, as expected. The slope is steeper at the medium flows between these two end states (the slope is about 6). This emphasises the point that the slope of the streamflow points on a recession plot is meaningless in terms of catchment storages at medium flows. Only the slopes of the quickflow and the laterecession streamflow (which is the same as the late-recession baseflow) have meaning in terms of storage types.

Figure $6 \mathrm{~d}$ shows the fraction of baseflow in the streamflow versus time according to the tracer-based BRM. Baseflow makes up $32 \%$ of the streamflow at the highest flow, then rises to $50 \%$ in about $3 \mathrm{~h}(0.12$ days), $75 \%$ at $14 \mathrm{~h}$ (0.6 days) and $95 \%$ at $43 \mathrm{~h}$ (1.8 days). The change from early to late recession is shown at 1.8 days.

\section{Discussion}

\subsection{A new baseflow separation method: advantages and limitations}

A new baseflow separation method (the BRM method) is presented. Advantages of the method are

1. It accurately simulates the shape of the baseflow or preevent component determined by tracers. This should mean that it gives more accurate baseflow separations and BFIs, because tracer separation of the hydrograph is regarded as the only objective separation method. The 

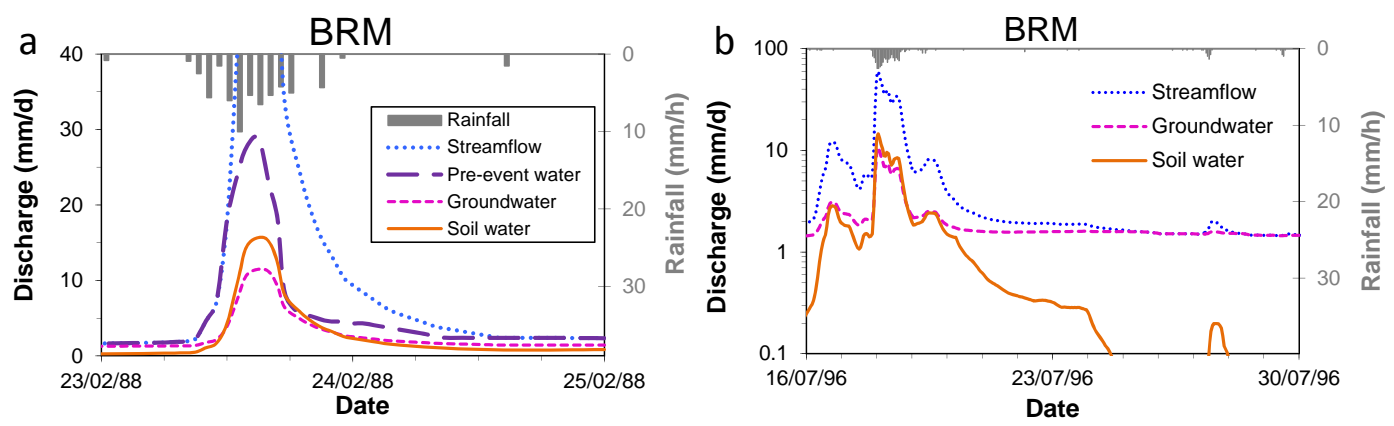

Figure 7. (a) and (b) showing groundwater and soil water components of the baseflow matched to the pre-event hydrograph. Streamflow is pre-event water plus event water.

BRM method involves a rapid response to rainfall (the "bump") and then a gradual increase with time following rainfall (the "rise").

2. The parameters $(f$ and $k$ ) quantifying the baseflow can be determined by fitting the baseflow to tracer hydrograph separations (as illustrated in Sect. 3.2) or by fitting the sum of the baseflow and a fast recession to the recession hydrograph under the constraint of a BFI determined by flow considerations (as illustrated in Stewart, 2014a).

3. The method can be applied using tracer data or streamflow data alone.

4. The method is easy to implement mathematically.

Current limitations or areas where further research may be needed are

1. Where there is no tracer data, specification of $f$ and $k$ depends on an initial estimate of the BFI, although the optimisation procedure means that the precise value estimated for the BFI is important, but not critical to the procedure.

2. The method produces an averaged representation of the baseflow hydrograph when applied to long-term data, so seasonal or intra-catchment variations are likely.

3. Separation of the hydrograph into three or more components (as shown by some tracer studies) could be explored. The next section considers three components.

\subsection{Calibration of the BRM algorithm}

This paper describes and demonstrates two ways of calibrating the BRM method (i.e. determining its parameters $f$ and $k$ ). These were also applied to the $\mathrm{H} \& \mathrm{H}$ and Eckhardt methods. These are (1) fitting the methods to tracer separations, and (2) applying an optimising or other procedure. The tracer-based (first way) is demonstrated in this paper, the optimising procedure (second way) was demonstrated in the early (unreviewed) version of this paper (Stewart, 2014a) and applied to the Eckhardt method in Stewart (2014b). Additional procedures put forward by Collischon and Fan (2013), based on characteristic flow duration curve flows $\left(Q_{90} / Q_{50}\right)$ and a backwards filter, are also compared with the other methods in this paper, but are not considered in detail.

Tracer separation of streamflow components depends on the tracer or tracers being used and the experimental methods. Klaus and McDonnell (2013) recently reviewed the use of stable isotopes for hydrograph separation and restated the five underlying assumptions. In the present case, deuterium was used by Bonell et al. (1990) to separate the streamflow into event and pre-event components (Fig. 2a). The pre-event component includes all of the water present in the catchment before the recorded rainfall event. The pre-event component therefore includes soil water mobilised during the event as well as groundwater. Three-component tracer separations have often been able to identify soil water contributions along with direct precipitation and groundwater contributions in streamflow (e.g. Iorgulescu et al. (2005) identified direct precipitation, acid soil and groundwater components in the Haute-Mentue Catchment, Switzerland; Fig. 2b).

The second way of calibrating the BRM assumes a value for the BFI and then uses this as a constraint to enable the sum (baseflow plus a fast recession) to be fitted to a streamflow recession (winter and summer events were examined in Stewart, 2014a). It is assumed that when the best-fit occurs (i.e. the baseflow has the optimum shape to fit to the streamflow) that the baseflow shape will be most similar to the "true" groundwater shape. The winter event BFI assumed is approximately in agreement with the BFIs given by the $\mathrm{H} \& \mathrm{H}$ and prescribed Eckhardt methods when applied to the 1996 streamflow record (the BFIs given by the $\mathrm{H} \& \mathrm{H}$, prescribed Eckhardt and winter BRM methods are 0.679, 0.617 and 0.622 , respectively). If this represents groundwater alone, then the difference with the pre-event water (or the BRM baseflow matched to it) is the soil water component as explained in Stewart (2014a). The groundwater and soil water components derived are shown in Fig. 7 for the 23 February 1988 event and 2-week period in 1996. The soil 
water component responds to rainfall more than the groundwater during events, then falls more rapidly after them. In the absence of tracers, it is not generally possible to identify the true groundwater component, but some BFI results appear to be "hydrologically more plausible" than others (quoted phrase from Eckhardt, 2008). The BFI assumed for the groundwater here is considered to be hydrologically plausible.

\subsection{Why is it necessary to apply baseflow separation to understand the hydrograph?}

The answer is straightforward: Because streamflow is a varying mixture of quickflow and baseflow components, which have very different characteristics and generation mechanisms and therefore give very misleading results when analysed as a mixture.

Previous authors (e.g. Hall, 1968; Brutsaert and Nieber, 1977; Tallaksen, 1995) addressed "baseflow recession analysis" or "low-flow recession analysis" in their titles, but nevertheless included both early and late parts of the recession hydrograph in their analyses. Kirchner (2009, p. 27) described his approach with the statement "the present approach makes no distinction between baseflow and quickflow. Instead it treats catchment drainage from baseflow to peak stormflow and back again, as a single continuum of hydrological behaviour. This eliminates the need to separate the hydrograph into different components, and makes the analysis simple, general and portable". This work contends that catchment runoff is not a single continuum, and the varying contributions of two or more very different components need to be kept in mind when the power-law slopes of the points on recession plots are considered. Lack of separation has probably led to misinterpretation of the slopes in terms of catchment storage reservoir types.

Kirchner's (2009) approach may be appropriate for his main purpose of "doing hydrology backwards" (i.e. inferring rainfall from catchment runoff), but the current author suggests that it gives misleading information about catchment storage reservoirs (as illustrated by the different slopes of streamflow, quickflow and probably baseflow in Fig. 6c). Note also that Kirchner's method is often used for recession analysis. Likewise Lamb and Beven's (1997) approach may have been fit-for-purpose for assessing the "catchment saturated zone store", but by combining parts of the early recession with the late recession may give misleading information concerning catchment reservoir type (and therefore catchment response). Others have used recession analysis on early and late streamflow recessions for diagnostic tests of model structure at different scales (e.g. Clark et al., 2009; McMillan et al., 2011) and it is suggested that these interpretations may have produced misleading information on storage reservoirs.

Evidence of the very different characteristics and generation mechanisms of quickflow and baseflow are provided by
1. The different timings of their releases to the stream (quick and slow) as shown by the early and late parts of the recession curve. (Note: the rapid response of slow storage water to rainfall (the "bump" in the BRM baseflow hydrograph) does not conflict with this because the bump is due to celerity not to fast storage.)

2. Many tracer studies (chemical and stable isotope) have shown differences between quickflow and baseflow, and substantiated their different timings of storage.

3. Transit times of stream waters show great differences between quickflow and baseflow. While quickflow is young (as shown by the variations of conservative tracers and radioactive decay of tritium), baseflow can be much older with substantial fractions of water having mean transit times beyond the reach of conservative tracer variations (4 years) and averaging 10 years as shown by tritium measurements (Stewart et al., 2010).

These considerations show that quickflow and baseflow are very different and in particular have very different hydrographs, so their combined hydrograph (streamflow) does not reflect catchment characteristics (except at low flows when there is no quickflow).

\subsection{A new approach to recession analysis}

It appears that streamflow recession analysis is a technique in disarray (Stoelzle et al., 2013). Different methods give different results and there is "a continued lack of consensus on how to interpret the cloud of data points" (Brutsaert, 2005). This work asserts that recession studies may have been giving misleading results in regard to catchment functioning because streamflow is a varying mixture of components (unless the studies were applied to late recessions only). The new approach of applying recession analysis to the separated quickflow component as well as streamflow may help to resolve this confusion, by demonstrating the underlying structure due to the different components in recession plots (as illustrated in Fig. 6c). Plotting baseflow from the late part of the recession may also be helpful. In particular, it is believed that recession analysis on quickflow, and late-recession baseflow as well as streamflow will give information that actually pertains to those components, giving a clearer idea than before on the nature of the water storages in the catchment, and contributing to broader goals such as catchment characterisation, classification and regionalisation.

Observations from the data set in this paper and from some other catchments to be reported elsewhere are

1. Quickflow appears to be quadratic in character (Sect. 7.2). This may result from a variety of processes such as surface detention, passage through saturated zones within the soil (perched zones) or within riparian zones near the stream. Whether this is true of catch- 
ments in a wider variety of climatic regimes remains to be seen.

2. The baseflow reservoirs at Glendhu appear to be quadratic in character, as has been previously observed at many other catchments by other authors (Brutsaert and Nieber, 1977; Wittenberg, 1999; Dewandel et al., 2003; Stoelzle et al., 2013). Hillslope and valley groundwater aquifers feed the water slowly to the stream.

3. The many cases of high power-law slopes $(d>1.5)$ in recession plots reported in the literature appear to be artefacts due to plotting early recession streamflow (particularly in the intermediate flow range) instead of separated components. This may have also contributed to the wide scatter of points generally observed in recession plots (referred to as "high time variability in the recession curve" by Tallaksen, 1995).

4. The most problematic parts of streamflow recession curves are those at intermediate flows when quickflow and baseflow are approximately equal. This is where steep power-law slopes are found. Data at high flows are dominated by quickflow, and baseflow contributes almost all of the flow at low flows, so these parts do not have such high power-law slopes.

5. Some other causes of scatter in recession plots are insufficient accuracy of measurements at low flows (Rupp and Selker, 2006), effects of rainfall during recession periods (most data selection methods try to exclude these), different rates of evapotranspiration in different seasons, different effects of rainfall falling in different parts of the catchment, contributions from snowmelt or wetlands or deeper groundwater systems and drainage from different aquifers in different dryness conditions (McMillan et al., 2011). These effects will be able to be examined more carefully when the confounding effects of baseflow are removed from intermediate flows.

6. Splitting the recession curve into early and late portions based on baseflow separation turns out to be a very useful thing to do. The early part has quickflow plus the confounding effects of baseflow, while the late part has only baseflow. The late part starts when baseflow becomes predominant (>95\%, Fig. 6d); this can be calculated by identifying the point where $B_{t} / Q_{t}=0.95$ during a recession. It appears that at Glendhu, the inflexion point records a change of slope in the baseflow and lies within the early part of the recession.

7. The close links between surface water hydrology and groundwater hydrology are revealed as being even closer by this work. Baseflow is mostly groundwater, and quickflow is also starting to look distinctly groundwater influenced (or saturation influenced). The success of groundwater models (Gusyev et al., 2013, 2014) in simulating tritium concentrations and baseflows in streams while being calibrated to groundwater levels in wells shows the intimate connection between the two. The feeling that catchment drainage can be treated as a single continuum of hydrological behaviour has probably prevented recognition of the disparate natures of the quick and slow drainages. This may be a symptom of the fact that surface water hydrology and groundwater hydrology can be regarded as different disciplines (Barthel, 2014). Others however are crossing the divide by examining geological controls on BFIs (Bloomfield et al., 2009) and relating baseflow simulation to aquifer model structure (Stoelzle et al., 2015).

\section{Conclusions}

This paper has two main messages. The first is the introduction of a new baseflow separation method (the bump and rise method or BRM). The advantage of the BRM is that it specifically simulates the shape of the baseflow or pre-event component as shown by tracers. Tracer separations are regarded as the only objective way of determining baseflow separations and BFIs, so the BRM method should give relatively more accurate baseflow separations and BFIs. The BRM parameters are determined by either fitting them to tracer separations (which are usually determined on a small number of events) as illustrated in this paper, or by estimating the BFI and using it as a constraint which enables determination of the BRM parameters by an optimisation procedure on an event or events as illustrated in an earlier version of this paper (Stewart, 2014a). The BRM algorithm can then be applied simply to the entire streamflow record.

Current limitations or areas where further research could be needed are (1) specification of $f$ and $k$ depends on tracer information or an initial estimate of the BFI, although the optimisation procedure means that the precise value estimated for the BFI is important but not critical to the procedure; (2) the method applied to long-term data produces an averaged representation of the baseflow hydrograph, so seasonal or intra-catchment variations are likely; and (3) separation of the hydrograph into three components (as shown by some tracer studies) could be explored (and has been for the Glendhu Catchment).

The second main message is that recession analysis of streamflow alone on recession plots can give very misleading results regarding the nature of catchment storages because streamflow is a varying mixture of components. Instead, plotting separated quickflow gives insight into the early recession flow sources (high to intermediate flows), and separated baseflow (which is equal to late streamflow) gives insight into the late-recession flow sources (low flows). The very different behaviours of quickflow and baseflow are evident from their different timings of release from storage (shown by the early and late portions of the recession curve, by tracer stud- 
ies, and by their very different transit times). Clearer ideas on the nature of the storages in the catchment can contribute to broader goals such as catchment characterisation, classification and regionalisation, as well as modelling. Flow duration curves can also be determined for the separated stream components, and these help to illuminate the make-up of the streamflow at different exceedance percentages.

Conclusions drawn from applying recession analysis to separated components in this paper are (1) many cases of high power-law slopes $(d>1.5)$ in recession plots reported in the literature are likely to be artefacts due to plotting early recession streamflow. The most problematic parts of streamflow recession curves are those at intermediate flows when quickflow and baseflow are approximately equal. This is where steep power-law slopes are found. (2) Both quickflow and baseflow reservoirs appear to be quadratic in character, suggesting that much stream water passes through saturated zones (perched zones in the soil, riparian zones, groundwater aquifers) at some stage. (3) Other causes of scatter in recession plots will be able to be examined more carefully when the confounding effects of baseflow are removed from intermediate flows. (4) Splitting the recession curve into early and late portions is very informative, because of their different make-ups. The late part starts when baseflow becomes predominant.

Some suggestions for the way forward in light of the findings of this paper are (1) recession analyses as well as transit time analyses and chemical-discharge relationships should be qualified with the component being analysed. This will make the significance of the results clearer. (2) Rainfall-runoff models should make more use of (nonlinear) quadratic storage systems for simulating streamflow. (3) Much more data on many other catchment areas needs to be examined in this way to develop and refine these concepts.

Acknowledgements. The author would like to thank Barry Fahey, John Payne and staff of Landcare Research NZL for data and cooperation on Glendhu Catchment studies. The editor (Jim Freer) and anonymous reviewers are thanked for their work with this paper.

Edited by: J. Freer

\section{References}

Barthel, R.: HESS Opinions "Integration of groundwater and surface water research: an interdisciplinary problem?", Hydrol. Earth Syst. Sci., 18, 2615-2628, doi:10.5194/hess-18-26152014, 2014.

Bazemore, D. E., Eshleman, K. N., and Hollenbeck, K. J.: The role of soil water in stormflow generation in a forested headwater catchment: synthesis of natural tracer and hydrometric evidence, J. Hydrol., 162, 47-75, 1994.

Beven, K. J.: Hydrograph separation?, in: Proceedings of the BHS 3rd National Hydrology Symposium, Southampton, 1991.
Beven, K. J.: Rainfall-runoff modelling: the primer, 2nd Edn., Wiley-Blackwell, Chichester, 2012.

Biswal, B. and Marani, M.: Geomorphological origin of recession curves, Geophys. Res. Lett., 37, L24403, doi:10.1029/2010GL045415, 2010.

Bloomfield, J. P., Allen, D. J., and Griffiths, K. J.: Examining geological controls on baseflow index (BFI) using regression analysis: An illustration from the Thames Basin, UK, J. Hydrol., 373, 164-176, doi:10.1016/j.jhydrol.2009.04.025, 2009.

Bonell, M., Pearce, A. J., and Stewart, M. K.: Identification of runoff production mechanisms using environmental isotopes in a tussock grassland catchment, Eastern Otago, New Zealand, Hydrol. Process., 4, 15-34, 1990.

Boussinesq, J.: Essai sur la théorie des eaux courantes, Memoires de l'Académie des Sciences de l'Institut de France, 23, 252-260, 1877.

Boussinesq, J.: Sur un mode simple d'écoulement des nappes d'eau d'infiltration á lit horizontal, avec rebord vertical tout autour lorsqu'une partie de ce rebord est enlevée depuis la surface jusqu'au fond, C. R. Acad. Sci., 137, 5-11, 1903.

Bowden, W. B., Fahey, B. D., Ekanayake, J., and Murray, D. L.: Hillslope and wetland hydrodynamics in a tussock grassland, Southland, New Zealand, Hydrol. Process., 15, 1707-1730, 2001.

Brutsaert, W.: Hydrology: An Introduction, Cambridge University Press, Cambridge, UK, 605 pp., 2005.

Brutsaert, W. and Nieber, J. L.: Regionalized drought flow hydrographs from a mature glaciated plateau, Water Resour. Res., 13, 637-643, 1977.

Buttle, J. M.: Isotope hydrograph separations and rapid delivery of pre-event water from drainage basins, Prog. Phys. Geogr., 18, 16-41, 1994.

Campbell, D. I. and Murray, D. L.: Water balance of snow tussock grassland in New Zealand, J. Hydrol., 118, 229-245, 1990.

Chapman, T. G.: A comparison of algorithms for streamflow recession and baseflow separation, Hydrol. Process., 13, 701-714, 1999.

Chapman, T. G. and Maxwell, A. I.: Baseflow separation - Comparison of numerical methods with tracer experiments, In Proceedings of the 23rd Hydrology and Water Resources Symposium, Hobart, Australia, 539-545, 1996.

Clark, M. P., Rupp, D. E., Woods, R. A., Tromp-van Meerveld, H. J., Peters, N. E., and Freer, J. E.: Consistency between hydrological models and field observations: linking processes at the hillslope scale to hydrological responses at the watershed scale, Hydrol. Process., 33, 311-319, 2009.

Collischon, W. and Fan, F. M.: Defining parameters for Eckhardt's digital baseflow filter. Hydrol. Process. 27, 2614-2622, doi:10.1002/hyp.9391, 2013.

Dewandel, B., Lachassagne, P., Bakalowicz, M., Weng, P., and AlMalki, A.: Evaluation of aquifer thickness by analysing recession hydrographs. Application to the Oman ophiolite hard-rock aquifer, J. Hydrol., 274, 248-269, 2003.

Eckhardt, K.: How to construct recursive digital filters for baseflow separation, Hydrol. Process., 19, 507-515, doi:10.1002/hyp.5675, 2005.

Eckhardt, K.: A comparison of baseflow indices, which were calculated with seven different baseflow separation methods, J. Hydrol., 352, 168-173, 2008. 
Fahey, B. D. and Jackson, R. J.: Hydrological impacts of converting native forest and grasslands to pine plantations, South Island, New Zealand, Agr. Forest Meteorol., 84, 69-82, 1997.

Fenicia, F., Savenije, H. H. G., Matgen, P., and Pfister, L.: Is the groundwater reservoir linear? Learning from data in hydrological modelling, Hydrol. Earth Syst. Sci., 10, 139-150, doi:10.5194/hess-10-139-2006, 2006.

Fenicia, F., Kavetski, D., and Savenije, H. H. G.: Elements of a flexible approach for conceptual hydrological modelling: 1. Motivation and theoretical development, Water Resour. Res., 47, W11510, doi:10.1029/2010WR010174, 2011.

Gonzales, A. L., Nonner, J., Heijkers, J., and Uhlenbrook, S.: Comparison of different base flow separation methods in a lowland catchment, Hydrol. Earth Syst. Sci., 13, 2055-2068, doi:10.5194/hess-13-2055-2009, 2009.

Gusyev, M. A., Toews, M., Morgenstern, U., Stewart, M., White, P., Daughney, C., and Hadfield, J.: Calibration of a transient transport model to tritium data in streams and simulation of groundwater ages in the western Lake Taupo catchment, New Zealand, Hydrol. Earth Syst. Sci., 17, 1217-1227, doi:10.5194/hess-171217-2013, 2013.

Gusyev, M. A., Abrams, D., Toews, M. W., Morgenstern, U., and Stewart, M. K.: A comparison of particle-tracking and solute transport methods for simulation of tritium concentrations and groundwater transit times in river water, Hydrol. Earth Syst. Sci., 18, 3109-3119, doi:10.5194/hess-18-3109-2014, 2014.

Hall, F. R.: Base-flow recessions - A review, Water Resour. Res., 4, 975-983, 1968.

Hangen, E., Lindenlaub, M., Leibundgut, Ch., and von Wilpert, $\mathrm{K}$.: Investigating mechanisms of stormflow generation by natural tracers and hydrometric data: a small catchment study in the Black Forest, Germany, Hydrol. Process., 15, 183-199, 2001.

Hewlett, J. D. and Hibbert, A. R.: Factors affecting the response of small watersheds to precipitation in humid areas, in: Forest Hydrology, edited by: Sopper, W. E. and Lull, H. W., Pergamon, Oxford, 275-290, 1967.

Holko, L., Herrmann, A., Uhlenbrook, S., Pfister, L., and Querner, E.: Ground water runoff separation - test of applicability of a simple separation method under varying natural conditions, Friend 2002 - Regional hydrology: Bridging the gap between research and practice, IAHS Publication no. 274, IAHS Press, Wallingford, 265-272, 2002.

Hooper, R. P. and Shoemaker, C. A.: A comparison of chemical and isotopic hydrograph separation, Water Resour. Res., 22, 14441454, 1986.

Hrachowitz, M., Savenije, H., Bogaard, T. A., Tetzlaff, D., and Soulsby, C.: What can flux tracking teach us about water age distribution patterns and their temporal dynamics?, Hydrol. Earth Syst. Sci., 17, 533-564, doi:10.5194/hess-17-533-2013, 2013.

Iorgulescu, I., Beven, K. J., and Musy, A.: Data-based modelling of runoff and chemical tracer concentrations in the Haute-Mentue research catchment (Switzerland), Hydrol. Process., 19, 25572573, 2005.

Iwagami, S., Tsujimura, M., Onda, Y., Shimada, J., and Tanaka, T.: Role of bedrock groundwater in the rainfall-runoff process in a small headwater catchment underlain by volcanic rock, Hydrol. Process,, 24, 2771-2783, doi:10.1002/hyp.7690, 2010.
Joerin, C., Beven, K. J., Iorgulescu, I., and Musy, A.: Uncertainty in hydrograph separations based on mixing models, J. Hydrol., 255, 90-106, 2002.

Kirchner, J. W.: A double paradox in catchment hydrology and geochemistry, Hydrol. Process, 17, 871-874, 2003.

Kirchner, J. W.: Catchments as simple dynamical systems: Catchment characterization, rainfall-runoff modelling, and doing hydrology backward, Water Resour. Res., 45, W02429, doi:10.1029/2008WR006912, 2009.

Klaus, J. and McDonnell, J. J.: Hydrograph separation using stable isotopes: Review and evaluation, J. Hydrol., 505, 47-64, 2013.

Lamb, R. and Beven, K.: Using interactive recession curve analysis to specify a general catchment storage model, Hydrol. Earth Syst. Sci., 1, 101-113, doi:10.5194/hess-1-101-1997, 1997.

Linsley, R. K., Kohler, M. A., and Paulhus, J. L.: Hydrology for Engineers, McGraw-Hill, New York, 1975.

Lyne, V. D. and Hollick, M.: Stochastic time-variable rainfall runoff modelling, in: Hydrology and Water Resources Symposium, Institution of Engineers Australia, Perth, 89-92, 1979.

McDonnell, J. J. and Beven, K. J.: Debates - The future of Hydrological Sciences: A (common) path forward? A call to action aimed at understanding velocities, clerities and residence time distributions of the headwater hydrograph, Water Resour. Res., 80, 5342-5350, doi:10.1002/2013WR015141, 2014.

McDonnell, J. J., Bonell, M., Stewart, M. K., and Pearce, A. J.: Deuterium variations in storm rainfall - Implications for stream hydrograph separation, Water Resour. Res., 26, 455-458, 1991.

McMillan, H. K., Clark, M. P., Bowden, W. B., Duncan, M., and Woods, R.: Hydrological field data from a modeller's perspective: Part 1. Diagnostic tests for model structure, Hydrol. Process., 25, 511-522, 2011.

Michel, R. L., Aggarwal, P., Araguas-Araguas, L., Kurttas, T., Newman, B. D., and Vitvar, T.: A simplified approach to analyzing historical and recent tritium data in surface waters, Hydrol. Process., 29, 572-578, doi:10.1002/hyp.10174, 2015.

Nejadhashemi, A. P., Shirmohammadi, A., and Montas, H. J.: Evaluation of streamflow partitioning methods, Pap. No. 032183 in ASAE Annual International Meeting, edited by: St. Joseph, M., Las Vegas, Nevada, USA, 2003.

Pearce, A. J., Rowe, L. K., and O'Loughlin, C. L.: Hydrology of mid-altitude tussock grasslands, upper Waipori catchment, Otago: II Water balance, flow duration and storm runoff, J. Hydrol. (NZ), 23, 60-72, 1984.

Pfister, L., McDonnell, J. J., Hissler, Ch., Klaus, J., and Stewart M. K.: Geological controls on catchment mixing, storage, and release, Hydrol. Process., in review, 2014.

Pinder, G. F. and Jones, J. F.: Determination of the groundwater component of peak discharge from the chemistry of total runoff, Water Resour. Res., 5, 438-445, doi:10.1029/WR005i002p00438, 1969.

Rupp, D. E. and Selker, J. S.: Information, artifacts and noise in $\mathrm{d} Q / \mathrm{d} t-Q$ recession analysis, Adv. Water Resour., 29, 154-160, 2006.

Searcy, R. K.: Flow-duration curves, Manual of Hydrology: Part 2. Low-flow techniques, Geological Survey Water-Supply paper 1542-A, US Government Printing Office, Washington, p. 33, 1959.

Shaw, S. B. and Riha, J. S.: Examining individual recession events instead of a data cloud: Using a modified interpretation of 
$\mathrm{d} Q / \mathrm{d} t-Q$ streamflow recession in glaciated watersheds to better inform models of low flow, J. Hydrol., 434-435, 46-54, 2012.

Sklash, M. G. and Farvolden, R. N.: The role of groundwater in storm runoff, J. Hydrol., 43, 45-65, 1979.

Sloto, R. A. and Crouse, M. Y.: HYSEP: A computer program for streamflow hydrograph separation and analysis, US Geological Survey, Water-Resources Investigations Report 96-4040, US Geological Survey, Lemoyne, Pennsylvania, 1996.

Smakhtin, V. U.: Low flow hydrology: A review, J. Hydrol., 240, 147-186, 2001.

Stewart, M. K.: New baseflow separation and recession analysis approaches for streamflow, Hydrol. Earth Syst. Sci. Discuss., 11, 7089-7131, doi:10.5194/hessd-11-7089-2014, 2014a.

Stewart, M. K.: Interactive comment on "New baseflow separation and recession analysis approaches for streamflow" by M. K. Stewart, Hydrol. Earth Syst. Sci. Discuss., 11, C3964C3964, 2014b.

Stewart, M. K. and Fahey, B. D.: Runoff generating processes in adjacent tussock grassland and pine plantation catchments as indicated by mean transit time estimation using tritium, Hydrol. Earth Syst. Sci., 14, 1021-1032, doi:10.5194/hess-14-10212010, 2010.

Stewart, M. K., Mehlhorn, J., and Elliott, S.: Hydrometric and natural tracer $\left({ }^{18} \mathrm{O}\right.$, silica, ${ }^{3} \mathrm{H}$ and $\left.\mathrm{SF}_{6}\right)$ evidence for a dominant groundwater contribution to Pukemanga Stream, New Zealand, Hydrol. Process., 21, 3340-3356, doi:10.1002/hyp.6557, 2007.

Stewart, M. K., Morgenstern, U., and McDonnell, J. J.: Truncation of stream residence time: How the use of stable isotopes has skewed our concept of streamwater age and origin, Hydrol. Process., 24, 1646-1659, 2010.
Stewart, M. K., Morgenstern, U., McDonnell, J. J., and Pfister, L.: The "hidden streamflow" challenge in catchment hydrology: A call to action for streamwater transit time analysis, Hydrol. Process., 26, 2061-2066, doi:10.1002/hyp.9262, 2012.

Stoelzle, M., Stahl, K., and Weiler, M.: Are streamflow recession characteristics really characteristic?, Hydrol. Earth Syst. Sci., 17, 817-828, doi:10.5194/hess-17-817-2013, 2013.

Stoelzle, M., Weiler, M., Stahl, K., Morhard, A., and Schuetz, T.: Is there a superior conceptual groundwater model structure for baseflow simulation?, Hydrol. Process., 29, 1301-1313, doi:10.1002/hyp.10251, 2015.

Su, N. G.: The Unit-Hydrograph Model for Hydrograph Separation, Environ. Int., 21, 509-515, 1995.

Tallaksen, L. M.: A review of baseflow recession analysis, J. Hydrol., 165, 349-370, 1995.

Vogel, R. and Kroll, C.: Regional geohydrogeologic-geomorphic relationships for the estimation of low-flow statistics, Water Resour. Res., 28, 2451-2458, 1992.

Westerberg, I. K., Guerrero, J.-L., Younger, P. M., Beven, K. J., Seibert, J., Halldin, S., Freer, J. E., and Xu, C.-Y.: Calibration of hydrological models using flow-duration curves, Hydrol. Earth Syst. Sci., 15, 2205-2227, doi:10.5194/hess-15-22052011, 2011.

Wittenberg, H.: Baseflow recession and recharge as nonlinear storage processes, Hydrol. Process., 13, 715-726, 1999.

Zhang, R., Li, Q., Chow, T. L., Li, S., and Danielescu, S.: Baseflow separation in a small watershed in New Brunswick, Canada, using a recursive digital filter calibrated with the conductivity mass balance method, Hydrol. Process., 27, 2659-2665, 2013. 